\title{
Requirements for Application of China's Vertical Takeoff and Landing UAV in Maritime Supervision
}

\author{
Zhu Jing \\ Dept. Automation and Information \\ Waterborne Transportation Institute of MOT \\ Beijing, China \\ zhujing@wti.ac.cn
}

\author{
Gu Qun, Liu Li \\ Lab of Maritime Traffic Safety Supervision \\ Waterborne Transportation Institute of MOT \\ Beijing, China \\ guqun@wti.ac.cn
}

\begin{abstract}
Unmanned vertical take-off and landing aircraft (VTOL UAV) will become an important maritime supervision platform in the future. The aim of this research was to give out basic requirements of using VTOL UAV in the field of maritime management. We studied duties of China's Maritime Safety Administration (MSA), and analyzed maritime tasks, then summarized what VTOL UAV can do in those tasks. Base on those task demand and sea working environment conditions, and also according experiments flight, the paper gives out the basic technical requirements of VTOL UAV from the points of task devices, application mode, platform technical parameters, flight and control, and wireless communications. The paper introduces using of shore-based and ship-based VTOL UAV, and concludes that it should reach the demand of endurance, wind resistance scale, platform ability respectively. The paper makes comparison to illustrate that the effects of different VTOL UAV flight height and base station height on the communication distance.
\end{abstract}

Keywords-VTOL UAV, unmanned helicopter; multi-rotors $U A V$; maritime supervision; communication; requirement

\section{INTRODUCTION}

The vertical takeoff and landing unmanned aircraft vehicle (VTOL UAV) has many advantages such as takes off and landing vertically, hovers long time, flight flexible etc. This application technology has been rapidly developed and popular used in military and civil fields all around the world.

In ordinary understanding, VTOL UAV is generally understood as a vertical take-off and landing of unmanned aerial vehicles. There are two kinds of VTOL UAV from the point of product marketing. One is traditional unmanned helicopter with single rotor and tail rotor (such like AV500 from Aviation Industry Corporation of China, AVIC) or with coaxial rotors (such like TD-220 from Beijing ZhongHangZhi Technology, ZHZ). The other one is multi-rotors UAV, which has 4,6 and 8 rotors (such like DJI Phantom series) mostly.

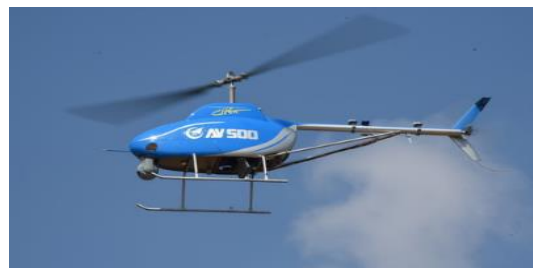

Fig. 1. AV-500 from AVIC, Single rotor with tail rotor

Fund program: The National Key Technologies R\&D Program (2012BAC14B05)
AV500 is a kind of multi-use VTOL UAV, which developed by AVIC. Its max takeoff weight can reach to $450 \mathrm{~kg}$, task load $80 \mathrm{~kg}, 6$ hours endurance. It has done maritime experiment flight on south east coast of China in 2016.

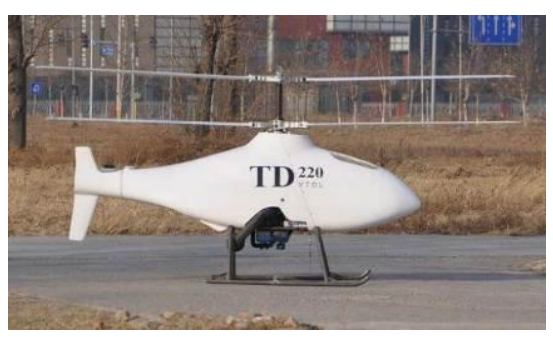

Fig. 2. TD-220 UAV from ZHZ, Coaxial twin rotors.

ZHZ's TD-220 UAV is a typical coaxial rotor VTOL UAV, which max takeoff weight is $290 \mathrm{~kg}$, with $80 \mathrm{~kg}$ of load and 5 hours endurance. The General Administration of Customs has signed a contract with ZHZ Technology Co Ltd. to equip TD220 in 2015

Now time, in the field of traditional unmanned helicopter of China, the performance is not good as world leading products (such like MQ-8B from Northrop Grumman US and S-100 from Schiebel Austria) due to the limitation of small aircraft engine.

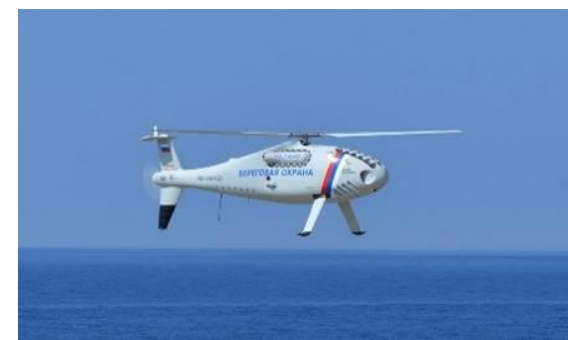

Fig. 3. S-100 from Schiebel, Austria

The MQ-8B and S-100 UAV both can work in ship-based application mode. The MQ-8B services to United States Navy developed from Schweizer 333 manned helicopter, [1] it equips a Rolls-Royce 250 turbine engine ran with JP-5 jet fuel. JP-5 is a kind of aviation kerosene with min flash point $65.6^{\circ} \mathrm{C}$, [2] which can support MQ-8B running and store on ship safely due to high flash point low fire risk. 


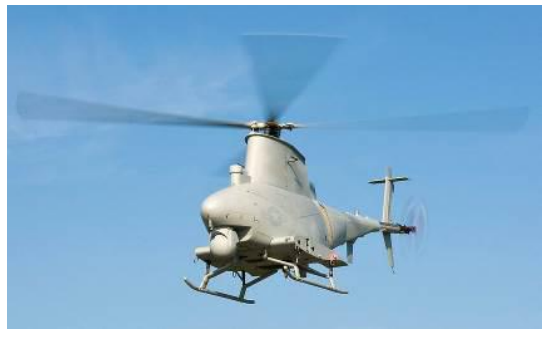

Fig. 4. MQ-8B Fire Scout UAV from Northrop Grumman, United States

The fuel engine powered VTOL UAV are all using gasoline as fuel in China, which doesn't support running or store on ships due to gasoline's low flash point $\left(-50^{\circ} \mathrm{C} \sim-20^{\circ} \mathrm{C}\right)$. China now doesn't have sea-based or ship-based unmanned helicopter still.

The unmanned multi-rotors vertical takeoff and landing technology started from 2005, and rapidly development from 2013. China has reached the international advanced level in terms of flight control technology, product performance and so on in multi-rotors UAV. DJI Technology has become a world well-known personal UAV manufacture and has the most shares in the world markets.
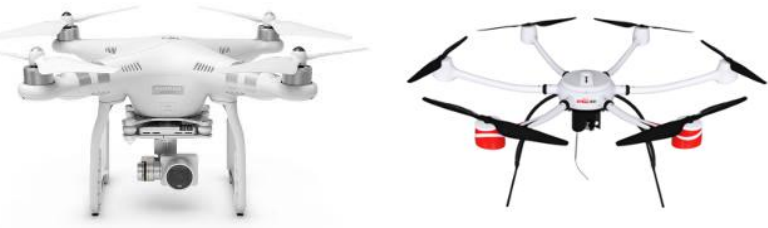

Fig. 5. Typical multi-rotors UAV, Left: DJI Phantom, Right:KEWEITAI X6

There are some of industrial use multi-rotors UAV, mainly are six rotors, it's easy to operate with good reliability, and can apply many kind of tasks. The X6 from Shenzhen KEWEITAI Technology has made some development focus on maritime rescue activities, such like voice broadcast, VHF repeater and deliver rescue materials, some of $\mathrm{X} 6$ have equipped on rescue ships.

At present, the VTOL UAV technology has been applied in the fields of State Grid supervision, survey and mapping, agriculture, movie-television and advertising, counter terrorism, personal entertainment, and other many industries, which has got remarkable achievements. [3]

With the implementation of China's marine power strategy, it causes the increase in marine activities, so it puts forward new requirements for marine management.

Marine management mainly includes sea surveillance, supervision, rescue, fishery administration, border inspection, suppress smuggling works, it mainly rely on ship cruising in the past years. The max speed of maritime cruising ship is about $18-22 \mathrm{knots}(33-40 \mathrm{~km} / \mathrm{h})$, so for a $100 \mathrm{~km}$ maritime cruising, it needs about $8-10$ hours which include sailing time and task time. It is low efficiency to long distance and large sea area cruising. And also, it is high cost for ship maritime cruising which includes the cost of ship fuel, crew and service etc.
Compared with the traditional maritime cruise mode, the VTOL UAV is flexible, fast and safe, so it will become an important platform for maritime cruising in the future. The Maritime Safety Administration (MSA) of Ministry of Transportation (MOT) has implemented research on unmanned helicopter maritime application from 2011. The Waterborne Transportation Institute (WTI) of MOT has carried out some VTOL UAV maritime cruising experiments on the coast of China.

Base on the research and experiments, we try to give out basic requirements of using VTOL UAV in field of maritime from tasks, supported devices, environment, UAV platform, flight plan and control, communication, etc.

\section{MARITIME SUPERVISION TASKS}

China MSA is the competent authority to exercise the administration of waterborne traffic safety, preventing pollution from ships, navigational service etc. The VTOL UAV involved in maritime tasks as shown in the following table.

TABLE I. TASK OF VTOL UAV IN MARITIME USE

\begin{tabular}{|c|c|c|c|}
\hline $\begin{array}{l}\text { Maritime } \\
\text { Duty MSA }\end{array}$ & Task Type & Task Description & $\begin{array}{l}\text { Unmanned } \\
\text { Helicopter } \\
\text { Functions }\end{array}$ \\
\hline \multirow{2}{*}{$\begin{array}{l}\text { Waterborne } \\
\text { Traffic } \\
\text { Safety }\end{array}$} & $\begin{array}{l}\text { Traffic } \\
\text { Accident }\end{array}$ & $\begin{array}{l}\text { Ship collision, } \\
\text { overturning, fire } \\
\text { accident } \\
\text { investigation and } \\
\text { evidence collection }\end{array}$ & $\begin{array}{c}\text { Flying, } \\
\text { hovering, video } \\
\text { photographing }\end{array}$ \\
\hline & $\begin{array}{l}\text { Traffic Illegal } \\
\text { Activity }\end{array}$ & $\begin{array}{l}\text { Violation of the } \\
\text { provisions of the } \\
\text { waterway, control } \\
\text { area and no } \\
\text { navigation area }\end{array}$ & $\begin{array}{c}\text { Flying, } \\
\text { hovering, } \\
\text { evidence and } \\
\text { communication }\end{array}$ \\
\hline \multirow{3}{*}{$\begin{array}{l}\text { Waterborne } \\
\text { Traffic } \\
\text { Order }\end{array}$} & $\begin{array}{c}\text { Traffic } \\
\text { Control } \\
\end{array}$ & $\begin{array}{l}\text { Maintenance control } \\
\text { area }\end{array}$ & $\begin{array}{l}\text { Cruise, video, } \\
\text { photographing }\end{array}$ \\
\hline & $\begin{array}{c}\text { Anchorages } \\
\text { Zone Manage }\end{array}$ & $\begin{array}{c}\text { Ship anchorage } \\
\text { supervision }\end{array}$ & $\begin{array}{l}\text { Cruise, video, } \\
\text { photographing }\end{array}$ \\
\hline & $\begin{array}{l}\text { Waterborne } \\
\text { Engineering }\end{array}$ & $\begin{array}{c}\text { Waterway } \\
\text { maintenance, wreck } \\
\text { salvage }\end{array}$ & $\begin{array}{l}\text { Cruise, video, } \\
\text { photographing }\end{array}$ \\
\hline \multirow{2}{*}{$\begin{array}{l}\text { Ship } \\
\text { Pollution } \\
\text { Preventing }\end{array}$} & $\begin{array}{c}\text { Pollution } \\
\text { Monitoring }\end{array}$ & $\begin{array}{l}\text { Marine oil spill, ship } \\
\text { pollution }\end{array}$ & $\begin{array}{l}\text { Cruise, video, } \\
\text { camera }\end{array}$ \\
\hline & $\begin{array}{c}\text { Sewage } \\
\text { Evidence }\end{array}$ & $\begin{array}{c}\text { Ship illegal evidence } \\
\text { collection }\end{array}$ & $\begin{array}{c}\text { Hovering, } \\
\text { evidence }\end{array}$ \\
\hline \multirow{2}{*}{$\begin{array}{l}\text { Navigation } \\
\text { Service }\end{array}$} & AtoN Manage & $\begin{array}{c}\text { AtoN operation } \\
\text { status check }\end{array}$ & $\begin{array}{l}\text { Cruise, video, } \\
\text { photographing }\end{array}$ \\
\hline & $\begin{array}{l}\text { Hydrographic } \\
\text { Survey }\end{array}$ & Marine surveying & $\begin{array}{l}\text { Cruise, video, } \\
\text { photographing }\end{array}$ \\
\hline \multirow{2}{*}{ Sea Rescue } & $\begin{array}{l}\text { Search and } \\
\text { Rescue }\end{array}$ & $\begin{array}{l}\text { Personnel search and } \\
\text { rescue in water }\end{array}$ & $\begin{array}{c}\text { Cruise, } \\
\text { hovering, } \\
\text { video, airdrop, } \\
\text { photographing, }\end{array}$ \\
\hline & $\begin{array}{l}\text { Accident Site } \\
\text { Monitoring }\end{array}$ & $\begin{array}{l}\text { Accident site } \\
\text { information }\end{array}$ & $\begin{array}{l}\text { Cruise, video, } \\
\text { hovering, } \\
\text { photographing, } \\
\text { communication }\end{array}$ \\
\hline
\end{tabular}

Functions of VTOL UAV apply in maritime supervision as follow:

- Cruising flight beyond line of sight on preset route.

- Hovering over the target, such as a person or a ship.

- Photographing with photoelectric devices,. 
- Target identification, include human, ship and AIS.

- Sea communications include real time video and other task information transmission, VHF, voice broadcast, communication relay.

- Airdrop of salvage items and equipment.

\section{MARITIME TASK DEVICES}

The VTOL UAV can use single or multi-combined task devices to carry out tasks according to maritime requirements. The most potential used devices as below.

\section{A. Airborne Photoelectric Pod}

Photoelectric pod is mainly used for image and video acquisition of ships and personnel on the sea, which has functions of automatic tracing, auto-focus, zoom, airborne recording, etc. There are two kind of optical sensors build in the pod normally, one is visible light, and the other one is infrared sensor.

In generally, a high resolution (720p or 1080p) CCD camera used as visible light sensor, and an infrared thermal imager as infrared sensor.

For the infrared sensor, there are two kind of resolution mostly used now time, which is $320 \times 256$ pixel and $640 \times 512$ pixel, higher resolution got better visual effects. You can also use cooled infrared technique to enhance your image and video quality, especially use in maritime oil pill monitoring, [4] we have made experiments on oil spill monitoring by this kind of pod. One thing you have to know that high resolution and cooled infrared technique causes your pod bigger and heavier, more important point is they are very expensive.
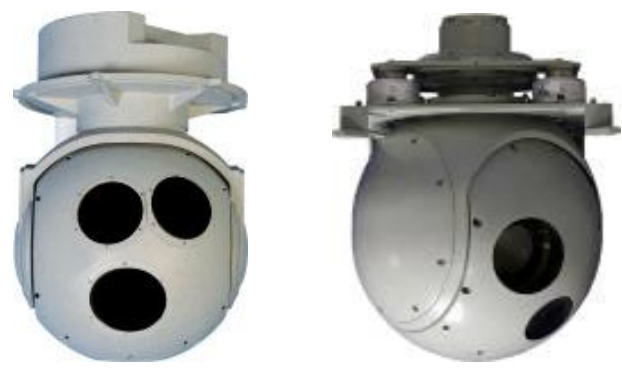

Fig. 6. Typical Electro-Optical / Infrared Pod

TABle II. Requirement of Photoelectric PoD

\begin{tabular}{|c|l|c|}
\hline Index & \multicolumn{1}{|c|}{ Requirements } & Parameters \\
\hline 1 & HD Camera resolution & $\begin{array}{c}720 \mathrm{p}, 1280 \times 720 \text { pixel } \\
1080 \mathrm{p}, 1920 \times 1080 \text { pixel }\end{array}$ \\
\hline 2 & Infrared imager resolution & $\begin{array}{c}320 \times 256 \text { pixel } \\
640 \times 512 \text { pixel }\end{array}$ \\
\hline 3 & Infrared enhance & Cooled medium-wave \\
\hline 4 & Ship recognize distance & $5-10 \mathrm{~km}$ \\
\hline 5 & Floating person recognize distance & $2-4 \mathrm{~km}$ \\
\hline 6 & Image process & H.264, H.265 \\
\hline 7 & Video and image storage & Local, high speed \\
\hline 8 & Stabilization & 3 -axis stabilization \\
\hline
\end{tabular}

\begin{tabular}{|c|l|c|}
\hline \multicolumn{2}{|c|}{ Cont. to table II } \\
\hline \multirow{2}{*}{9} & Weight & Small VTOL \\
& & UAV: $<30 \mathrm{~kg}$ \\
& & Multi-rotors UAV $:<5 \mathrm{~kg}$ \\
\hline 10 & Working temperature & $-20^{\circ} \mathrm{C} \sim 45^{\circ} \mathrm{C}$ \\
\hline
\end{tabular}

\section{B. VHF Device}

VHF is the main way of communication for ship-ship and shore-ships on sea. Unmanned helicopter use VHF devices to expand the communication distance between MSA command center (on ship or on shore) and ships in accident by its own communication connections. The VHF devices should cover the IMO maritime channels, from $156.050 \mathrm{MHz} 161.775 \mathrm{MHz}$.

\section{Airborne AIS Device}

The VTOL UAV can obtain the identity information of the ship within the surveillance area by the airborne AIS devices. This can help maritime regulators to recognize and bind ship identity information with relevant emergency or violations events.

\section{Voice Broadcasting Device}

The maritime regulators can broadcasting to the personnel who are in emergency or violation situation by airborne directional voice broadcasting device on the VTOL UAV. The voice information of maritime regulator will be transferred from MSA command center to sea site by VTOL UAV's own data links.

\section{E. Airdrop Device}

Maritime search and rescue is an important part of maritime management, and using VTOL UAV drop lifesaving supplies during sea search and rescue will improve the survival rate of drowning personnel. The unmanned helicopter can drop life jacket, buoy, positioning device and even food and drink water, etc.

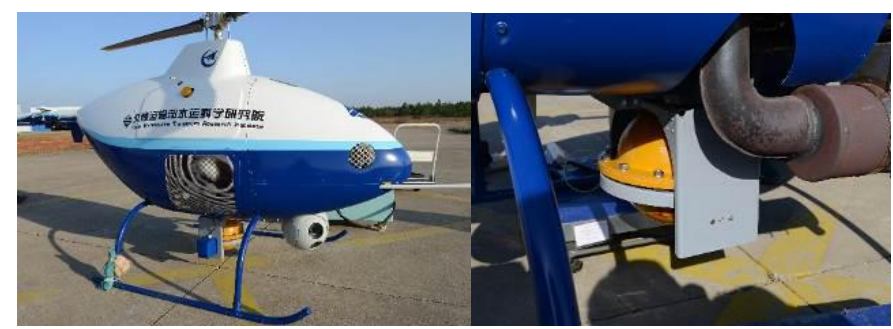

Fig. 7. A Rotary Airdrop Device Equiped on an AV-200 UAV, WTI

\section{F. Attention}

All these devices can be single use and combined use on one VTOL UAV, but they should meet the feasibility and safety demands of unmanned helicopter in mechanical, weight, shape, electrical, communication, etc..

\section{INFLUENCE FACTORS FORM MARITIME ENVIRONMENT}

Wind is the most critical factor impact to VTOL UAV using on the sea, especially on the phase of takeoff, hovering and landing. According to the relevant data from the China 
Meteorological Administration, the annual average wind speed of the coastal areas in China is as follows [5].

TABLE III. Average Wind SpeEd of China's Coastal

\begin{tabular}{|c|c|}
\hline Geographical region & Wind Speed $(\mathbf{m} / \mathbf{s})$ \\
\hline Coastal of Guangdong and Hainan & $5.5-5.7$ \\
\hline Coastal of Fujian & $7-9$ \\
\hline Coastal of Zhejiang and north & $6-7.5$ \\
\hline
\end{tabular}

The year average wind is in level $4-5(5.5-10.7 \mathrm{~m} / \mathrm{s})$ on Chia's costal line. Considering the practical application, the VTOL UAV should have a strong wind resistance ability, which should be more than level $6(10.8-13.8 \mathrm{~m} / \mathrm{s})$ at least, level $7(13.9-17.1 \mathrm{~m} / \mathrm{s})$ would be better. [6][7]

The VTOL UAV will face to corrosion from mildew, moisture, salt spray, etc. due to coastal running and store in long term. It is important to have strong ability of anti-mildew, anti-moisture and anti-salt.

Once the unmanned helicopter fall into sea, it should have water resistance ability in certain degree, such as important mechanics, electronics, etc. It should also have floating and positioning functions to be easy found and salvaged.

\section{VTOL UAV PLATFORM}

According to General Plan of National Coastal Shipping Route[8] released by MSA China and ships flow information of China's coastal, and also base on the data of maritime rescue events, we think the VTOL UAV maritime cruising should cover $150 \mathrm{~km}$ off coast, especially $100 \mathrm{~km}$ off coast.

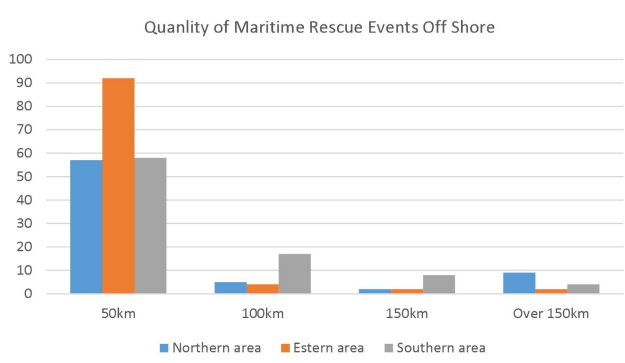

Fig. 8. Maritime Rescue Events on China's Costal

\section{A. VTOL UAV System Composition}

The maritime used VTOL UAV is composed of platform, local control station and maritime task devices.

Platform is composed of body structures, engine or power system, electrical and electronics, flight control, positioning and navigation system, wireless communication unit, etc.

Local control station is the command center that can make flight plan and route, control UAV takeoff or landing, operate maritime task device on UAV remotely, and also deal with emergencies situation, etc.

It can send real time video and pictures from sea site, and can use dedicated link to connect to MSA's command center.

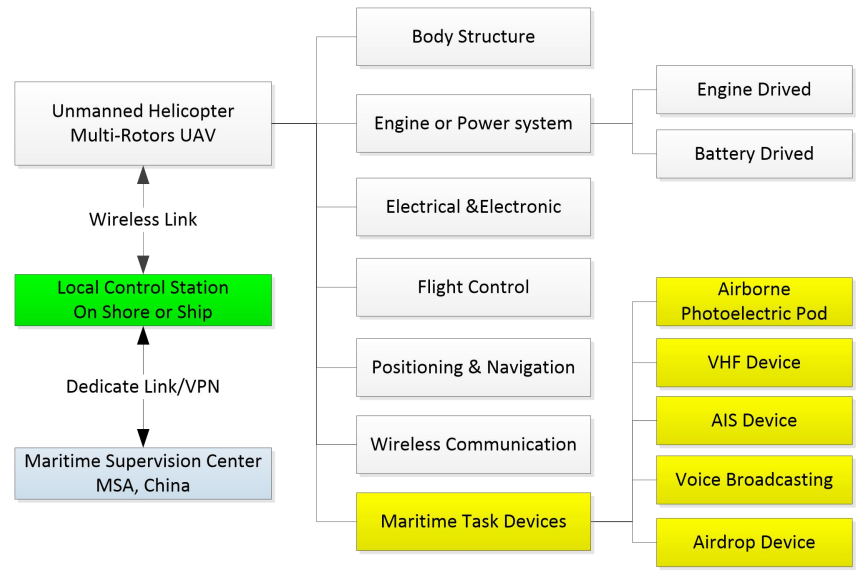

Fig. 9. Maritime VTOL UAV System Composition

Normally, the local control station of UAV is moveable; the functions should be composed of flight plan, flight monitoring and control, maritime task device operation. It can move with VTOL UAV via an appropriative or integrated in UAV's transportation vehicle.

There are two application modes for VTOL UAV, one is shore based, and the other one is ship based. Shore based application is mainly responsible for the port area and coastal area which is within $150 \mathrm{~km}$. Ship based application try to expand the search and monitoring ability for the maritime supervision and rescue ships.

\section{B. Shore Based Application}

In shore based mode, the VTOL UAV will takeoff from shore station, implement maritime task over sea area, return and landing on shore finally. Considering the distance of whole flight route to fit off shore $150 \mathrm{~km}$ requirements, the unmanned helicopter should be a kind of long endurance and with high cruising speed product.

Small scale unmanned helicopter which has max takeoff weight over $200 \mathrm{~kg}$ will fit to this using due to it has longer flight time and more payload ability. The platform should meet technical requirements as follow table.

TABLE IV. SHORE BASED APPLICATION REQUIREMENTS

\begin{tabular}{|c|l|c|}
\hline Index & \multicolumn{1}{|c|}{ Technical Requirements } & Parameter \\
\hline 1 & Max Takeoff Weight $(\mathrm{kg})$ & $>200$ \\
\hline 2 & Cruise Speed $(\mathrm{km} / \mathrm{h})$ & $>100$ \\
\hline 3 & Range $(\mathrm{km})$ & $>100$ \\
\hline 4 & Task Load Weight no Gasoline $(\mathrm{kg})$ & $>2000$ \\
\hline 5 & Maximum Flight Altitude $(\mathrm{m})$ & $>4$ \\
\hline 6 & Endurance $(\mathrm{h})$ & $>6$ \\
\hline 7 & $\begin{array}{l}\text { Wind Resistance of Takeoff, Landing } \\
\text { and Hovering (Beaufort scale) }\end{array}$ & $\begin{array}{c}\text { Gasoline or aviation } \\
\text { kerosene }\end{array}$ \\
\hline 8 & Engine Type &
\end{tabular}

\section{Ship Based Application}

In ship based mode, the VTOL UAV take off from ship, implement maritime task over sea area, return and landing on ship finally. As mentioned in the part of introduction, the small 
scale unmanned helicopter of China uses gasoline engine mostly in present, it is dangerous to working and store on ship due to easy cause fire.

The multi-rotors UAV driven by batteries will fit to this application, it can fly around a ship in range of $10 \mathrm{~km}$. It is a no alternative solution at present day. It should meet technical requirements as follow table.

TABLE V. SHIP BASED APPLICATION REQUIREMENTS

\begin{tabular}{|c|l|c|}
\hline Index & \multicolumn{1}{|c|}{ Technical Requirements } & Parameter \\
\hline 1 & Max Takeoff Weight $(\mathrm{kg})$ & $>15$ \\
\hline 2 & Cruise Speed $(\mathrm{km} / \mathrm{h})$ & $>50$ \\
\hline 3 & Range $(\mathrm{km})$ & $\nless 10$ \\
\hline 4 & Task Load Weight no Batteries $(\mathrm{kg})$ & $>5$ \\
\hline 5 & Maximum Flight Altitude $(\mathrm{m})$ & $>1$ \\
\hline 6 & Endurance (h) & $>600$ \\
\hline 7 & $\begin{array}{l}\text { Wind Resistance of Takeoff, Landing and } \\
\text { Hovering (Beaufort scale) }\end{array}$ \\
\hline
\end{tabular}

Ship based multi-rotors UAV should has the ability of ship autonomous takeoff and landing, corporate with ship, accompanying flight, anti-electromagnetic, etc.

\section{FLIGHT Plan AND CONTROL}

The VTOL UAV in flight control should have function below.

\section{A. Intelligent autonomous takeoff, flight, hovering and landing.}

The VTOL UAV should takeoff from shore base or ship deck automatically by the control system itself and same as landing. It can fly according to pre-planning flight route automatically or intelligently, and also make long time hovering over a target floating on sea automatically which without man manual operations.

\section{B. Autonomous return and landing once communication is lost.}

For safety reasons, the VTOL UAV should return back to a preassigned base on shore or ship automatically once the wireless communication is lost between the local control center and the VTOL UAV. In ship based application mode, it should considering that ship is floating or navigating on the sea, the position coordinate of the ship is unfixed.

\section{Support development flight route, and change rapidly even in flight.}

The operators can use UAV system application in local control station to development flight plan and flight route rapidly and also can change and load to UAV's control system in real time during flying time.

\section{Support rapid switch between manual remote control and autonomous flight.}

In the mission of maritime, the operator needs to search and watch targets or events out of the flight route in temporary, so the UAV's control system should allow the operator make switch from autonomous fly to man manual operation mode, and it can switch back to autonomous mode again.

\section{E. "Fool Operation" idea}

The operation and control of VTOL UAV should have "fool" idea. For better use in maritime supervision, we think it is good to the operator who comes from non-professional manipulator mostly.

The VTOL UAV's flight control system should sense the detail of operation; the computing system can analyze and get rid of dangerous flight behavior intelligently. This idea can dispense with relying of professional manipulators, and make the UAV system easy to use.

\section{WIRELESS COMMUNICATION}

The wireless communication between VTOL UAV and base station is an important factor in maritime using. It is useless if the communication coverage is not enough, even if the unmanned helicopter power, fuel, machinery can support it to fly farther.

Because of the curvature of the earth, the control and video information transmit distance between the flight distance and flight height is closely related.

At present, unmanned helicopter communications generally use high-frequency microwave communications, the unmanned helicopter can send back a $4 \mathrm{Mbps}$ of $1080 \mathrm{p}$ video stream in real time. The most distance calculating formula of microwave signal linear transmission is:

$$
\operatorname{Rmax}=4.12(\sqrt{H}+\sqrt{h})
$$

$\mathrm{R}_{\max }$ : the most distance linear transmission

$\mathrm{H}$ : height of base station antenna

h: unmanned helicopter antenna

Under normal circumstances, the altitude of the unmanned helicopter flying below 1000 meters, mostly below 300 meters. For instance, assuming the base station altitude is in sea level, the maximum distance with different altitude of unmanned helicopter is shown below.

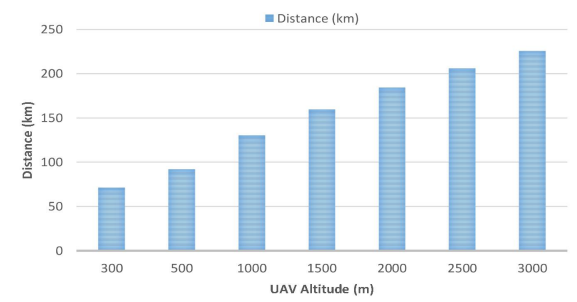

Fig. 10. Relationship Between Communication Distance and UAV Altitude

Communication base station and unmanned aerial vehicle under different altitude conditions, the longest distance calculation results as shown in the following figure. 


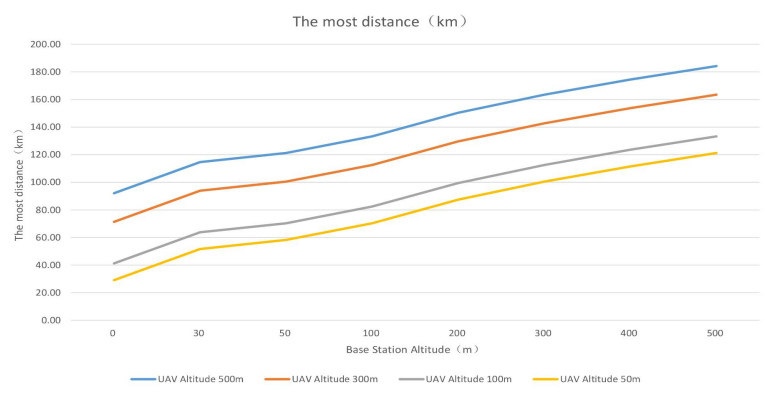

Fig. 11. Distance Influence From Base Station Altitude and UAV Altitude

It can be seen from the figure, as far as possible to increase the communication station location height can effectively improve the working distance of the VTOL UAV.

For instance, if communication base station is arranged in the $500 \mathrm{~m}$ position, flight height of $50 \mathrm{~m}$ can reach $100 \mathrm{~km}$ working distance. Under such conditions, the VTOL UAV can more close to the target on the sea.

In the absence of the communication base station could be arranged in a higher position, it should increase quantity of base station along the flight route, and the unmanned helicopter should and can work with multi base station.

\section{CONCLUSIONS}

In summary, in the promotion of China's maritime supervision system of unmanned helicopter application should consider the comprehensive coordination of many aspects of the platform performance, communication link and task load, focus on intelligent platform, but also pay attention to simple maintenance.

- The VTOL UAV maritime cruising should cover $150 \mathrm{~km}$ off coast, especially $100 \mathrm{~km}$ off coast.
- At present, small scale VTOL UAV with long endurance and strong wind resistance is fit shore base use.

- The multi-rotors UAV system is the better solution in use of ship base now.

- It better to establish long distance communication that put base station at a higher location.

- "Fool Operation" idea will make the use of VTOL UAV on maritime easy and safe.

- Thinking about using VTOL UAV under the sea environment, the UAV should have the ability of floating on sea, and easy to salvage.

- Developing safe fuel engine driven UAV is very necessary and in urgent.

\section{REFERENCES}

[1] Wanghao, "MQ-8B Multirole Unmanned Helicopter of US" International Aviation, 2007.2

[2] Jiao Yan, Feng Lili, Zhu Yuelin, Xiong Changjian, "Revies of American military jet fuels development", Journal of Rocket Propulsion, 2008.02, Vol 34, No.1

[3] Daijun, Guanyufeng, Renshuhong "Discuss in Current Situation and Development Trend of Multi-rotors UAV", Journal of Chifeng University, 2016.08

[4] Shi Yifan, Sun Jian, Huh Hao, "Route Planning for Offshore oil Spill Monitoring and Detection with UAV", Navigation of China, 2014.03, Vol.37 No.1

[5] Baoleer Qimuge, "Research on the Wind Characteristics of China Coastal Area", 2011, unpublished

[6] Xiaoguanghua, Zhangzhengyuan "The Development and Key Technology in Ship Based VTOL UAV" Papers of Chinese UAV Conference, 2014

[7] Fengzhenyu, "International and Domestic Meteorological Scale" China Ship Survey, 2015.8

[8] MOT, "General Plan of National Coastal Shipping Route", 2011 